\title{
Interfacial Crystallization of Isotactic Polypropylene Surrounding Macroscopic Carbon Nanotube and Graphene Fibers
}

John P. Abdou ${ }^{1}$, Karina J. Reynolds ${ }^{1}$, Michaela R. Pfau ${ }^{1}$, Justin van Staden ${ }^{1}$, Gregory A.

Braggin $^{1}$, Navid Tajaddod ${ }^{2}$, Marilyn Minus ${ }^{2}$, Víctor Reguero ${ }^{3}$, Juan J. Vilatela ${ }^{3}$, and Shanju Zhang ${ }^{1} *$

${ }^{1}$ Department of Chemistry and Biochemistry, California Polytechnic State University, San Luis Obispo, California 93407, United States

${ }^{2}$ Department of Mechanical and Industrial Engineering, Northeastern University, Boston, Massachusetts 02115, United States

${ }^{3}$ IMDEA Materials Institute, Getafe, Madrid 28906, Spain

*Corresponding author

Phone: + 1805756 2591. Fax: + 1805756 5500. E-mail: $\underline{\text { szhang05@ calpoly.edu }}$ 


\section{Abstract}

A comparative study on interfacial crystallization of isotactic polypropylene (iPP) surrounding macroscopic carbon nanotube and graphene fibers has been carried out in single fiber polymer composites by means of in situ polarized optical microscope, scanning electron microscope and X-ray diffraction. Ordered interfacial microstructures of iPP nucleate on both nanocarbon fibers in the form of a transcrystalline interphase. Nanotube fibers tend to promote negative birefringence transcrystals whereas graphene fibers induce positive birefringence transcrystals. The microstructures of transcrystals are strongly dependent on the thermal history and the double-layered transcrystals consisting of a negative inner layer and a positive outer layer occur under certain conditions. Transcrystallization kinetics has been studied and the Lauritzen-Hoffman theory of heterogeneous nucleation used to analyze the dynamic crystallization process. While the fold surface energy of iPP transcrystals surrounding both nanocarbon fibers shows little difference, the nanotube fiber promotes shorter induction time than the graphene fiber. Thermal resistance test demonstrates that the ordered interfacial microstructures possess higher melting temperature in the nanotube fiber composites than those in the graphene fiber composites. Under appropriate conditions, the $\beta$-form transcrystals of iPP are observed. The amount of the $\beta$-form iPP surrounding the nanotube fiber is much higher than that surrounding the graphene fiber. A theoretical model is proposed to interpret the difference between the nanotube and graphene fiber composites and the mechanisms behind its influence on interfacial crystallization.

Keywords: interfacial crystallization, transcrystals, isotactic polypropylene, carbon nanotubes, graphene, fiber 


\section{Introduction}

Nanocarbons, such as carbon nanotubes and graphene, have been considered as effective reinforcing nanofillers for the production of functional polymer nanocomposites for various emerging applications.[1-5] Nanotubes and graphene possess a unique combination of properties, including the high specific surface area, exceptional mechanical properties, high carrier mobility and outstanding thermal conductivity. A common strategy to exploit these "molecular" properties is by combining the nanocarbon with a polymer matrix, to form a composite. Polymer nanocomposites reinforced by nanotubes and graphene have different reinforcement efficiencies[6], but both share in common the important role of the large nanocarbon/polymer interface arising from their high surface-to-volume ratio.

It is well known that the interfacial interactions between the polymer and nanofillers are determinative to the reinforcement efficiency.[7-12] In particular, the nanofillers in the semicrystalline polymers can act as heterogeneous nucleating agents for promoting polymer crystallization at interfaces.[10-12] It has been reported that both nanotubes and graphene accelerate polymer crystallization when they have strong interactions with polymers.[13-17] The resulting interfacial crystals possess different microstructures and morphologies as compared to those in the bulk in terms of polymer chain orientation and crystal polymorphism. Importantly, the ordered interfacial microstructures significantly improve the interfacial adhesion and load transfer.[18-20] As a result, the mechanical performance,[12] thermal properties[21] and electrical conductivities[22] of the polymers have been greatly enhanced. 
Recent advances in nanocarbons allow the production of continuous macroscopic fibers made of nanotubes[23-25] or graphene.[26-28] When the nanotube or graphene fibers are embedded in the polymer matrix, the polymer crystals grow perpendicular to the long axis of nanocarbon fibers, resulting in the oriented lamellar microstructures at interfaces that are termed as transcrystals.[29-32] Most recently, it has been reported that many semicrystalline polymers can grow transcrystals in the present of nanotube fibers and a soft-epitaxy model has been proposed.[33] Interestingly, the crystal polymorphism often occurs in the transcrystalline layer.[29,30,34] The single-fiber pull-out tests have demonstrated that transcrystalline microstructures markedly improve interfacial adhesion and stress transfer.[31,32] Clearly, polymer transcrystallization induced by the nanocarbon fibers is a facile approach to investigate interfacial interactions between polymers and nanocarbons.

Isotactic polypropylene (iPP) is one of the most widely studied polyolefins and there exists three possible polymorphic crystal forms: monoclinic $\alpha$, hexagonal $\beta$, and orthorhombic $\gamma$.[35] The $\alpha$-form of iPP is the most common crystal form, while the $\beta$ and $\gamma$-forms are unstable and only achieved under the specific conditions. Interestingly, the $\beta$ - and $\gamma$-form iPPs exhibit better mechanical properties than the $\alpha$-form iPP.[36,37] In this work, iPP is chosen as a model system to study polymer transcrystallization and crystal polymorphism in the presence of the nanocarbon fibers. In particular, we systematically investigate the dynamic process of iPP transcrystallization surrounding both nanotube and graphene fibers. To the best of our knowledge, these results are the first experimental comparative study showing the different reinforcement mechanisms. 
We put forward arguments that interpret why carbon nanotubes and graphene fibers behave differently when they are mixed with the polymer matrix.

\section{Experimental Section}

Graphene oxide $(\mathrm{GO})$ was prepared in our own laboratory from natural graphite flakes via a modified Hummers' method.[38] The GO fibers were spun from a 5-10 mg/mL aqueous dispersion of GO via wet coagulation and they were subsequently reduced using an aqueous solution of $30 \%$ hydroiodic acid.[30] Carbon nanotube fibers were produced by the chemical vapor deposition (CVD) direct spinning method, using parameters leading to the formation of mutiwalled nanotubes of 3-5 layers and a winding rate of 40 $\mathrm{m} / \mathrm{min}$ (corresponding roughly to a draw ratio of 12.5 ) as described in a previous work.[39] As comparison, a wet-coagulation method was also used to spin nanotube fibers.[29]

The iPP was purchased from Aldrich and used as received (Melt index $=4.00 \mathrm{~g} / \mathrm{min}$, $\overline{M_{n}}=9.70 \times 10^{4} \mathrm{~g} / \mathrm{mol}, \overline{M_{w}}=3.43 \times 10^{5} \mathrm{~g} / \mathrm{mol}$ ). Single-fiber polymer composites were produced by introducing nanotube or graphene fibers into the films of iPP and hot pressed at $200{ }^{\circ} \mathrm{C}$ to get the composite structures. The specimens were heated to $200{ }^{\circ} \mathrm{C}$ for $5 \mathrm{~min}$ to erase the previous thermal history and subsequently cooled to the desired isothermal crystallization temperature at $20^{\circ} \mathrm{C} / \mathrm{min}$ to grow transcrystals. There was no fiber pulling or shearing during melting and crystallization. The Linkam LTS420 hotstage was programmed using the Linksys32 software to control the temperature with $0.1^{\circ} \mathrm{C}$ accuracy. 
The dynamic process of polymer transcrystallization was investigated using a Leica DM2500P polarized optical microscope (POM) that was connected with the Linkam LTS420 hot-stage. The Leica ICC50 HD video camera was employed to record the dynamic process. The morphologies of the fibers and transcrystallized specimens were studied on a FEI Quanta 200 scanning electron microscope (SEM) operated at an acceleration voltage of $20 \mathrm{kV}$. To reveal the lamellar morphology of transcrystals, the crystallized specimens were etched for 2-4 h with a $1.0 \mathrm{wt} \%$ solution of $\mathrm{KMnO}_{4}$ in the mixed acids of $98 \% \mathrm{H}_{2} \mathrm{SO}_{4}$ and $85 \% \mathrm{H}_{3} \mathrm{PO}_{4}$ by a volume ratio of $2: 1$ under ultrasonication.[30] The etched samples were then sputtered with a fine gold layer for SEM imaging. Two-dimensional wide-angle X-ray diffraction (2D WAXD) patterns were collected on a Rigaka S-Max $3000+007$ HFM system $(\lambda=1.5418 \AA)$ in a transmission mode. The diffraction patterns were analyzed using Rigaku NANO-SolverTM and Jade MDI Jade software.

\section{Results and Discussion}

\subsection{Transcrystallization}

Both nanotube and graphene fibers were used for investigation of iPP transcrystallization in the single fiber polymer composites. Fig. 1 shows typical SEM images of nanotube and graphene fibers. Both nanocarbon fibers are comparable in terms of fiber diameter. They are $30-60 \mu \mathrm{m}$ in diameter depending on fiber spinning conditions. Interestingly, the nanocarbon fibers display a different surface morphology. The surface of the nanotube fiber is smooth (Fig. 1a) and close examination reveals groove-like nanostructures that are composed of aligned nanotube bundles (Fig. 1b). In contrary, the graphene fibers 
exhibit the wrinkled rGO sheets (Fig. 1c), leading to large micro-grooves and rough surfaces (Fig. 1d).
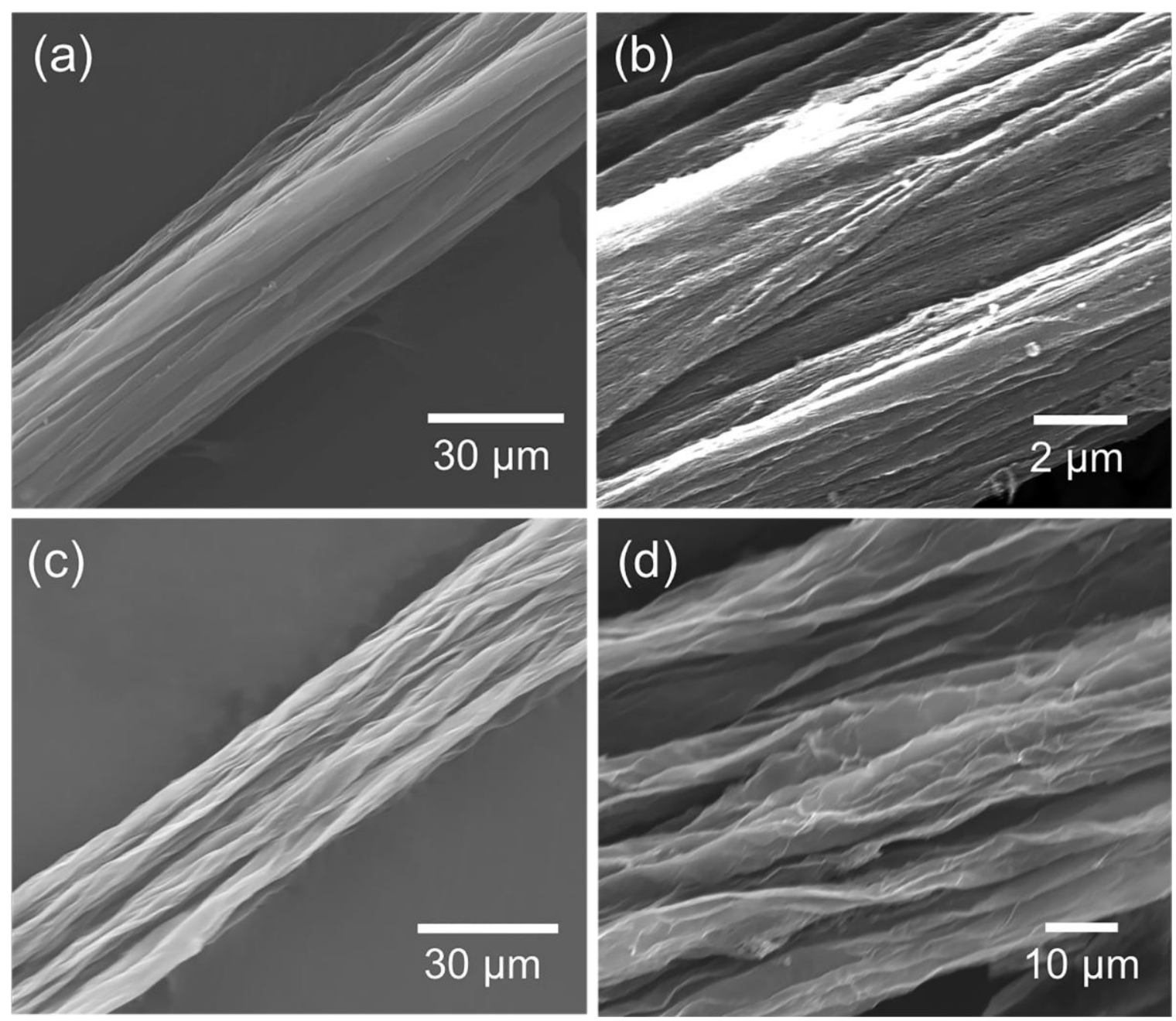

Fig. 1. Scanning electron micrographs of the nanocarbon fibers. (a) and (b) are nanotube fibers; (c) and (d) are graphene fiber fibers.

Fig. 2 displays typical optical micrographs of nanocarbon fiber/iPP composites in the presence of a retardation plate after isothermal crystallization. Clearly, the iPP displays a columnar growth of spherulites surrounding both nanotube and graphene fibers. These oriented interfacial microstructures are identified as transcrystals (TCs).[40] The transcrystals surrounding both nanotube and graphene fibers show mixed blue and orange contrast irregularly, indicating mixed birefringence crystals.[41] Upon rotation of the 
sample, the blue and orange contrast of transcrystals changes accordingly. The transcrystals on the nanotube fiber are well aligned and they display dominant orange contrast in the one-three quadrant phase (in a web version), in particular in the vicinity of the nanotube fiber (Fig. 2a). On contrary, the transcrystals on the graphene fibers are less aligned and they exhibit most blue contrast in the one-three quadrant phase (Fig. 2b). In general, the positive birefringence spherulites exhibit blue in the one-three quadrant phase and orange in the two-four quadrant phase, whereas the negative birefringence spherulites display orange in the one-three quadrant phase and blue in the two-four quadrant phase.[31,41] Thus, our data demonstrates that the transcrystals surrounding CNT fibers have negative birefringence whereas those surrounding the graphene fibers have the positive birefringence.
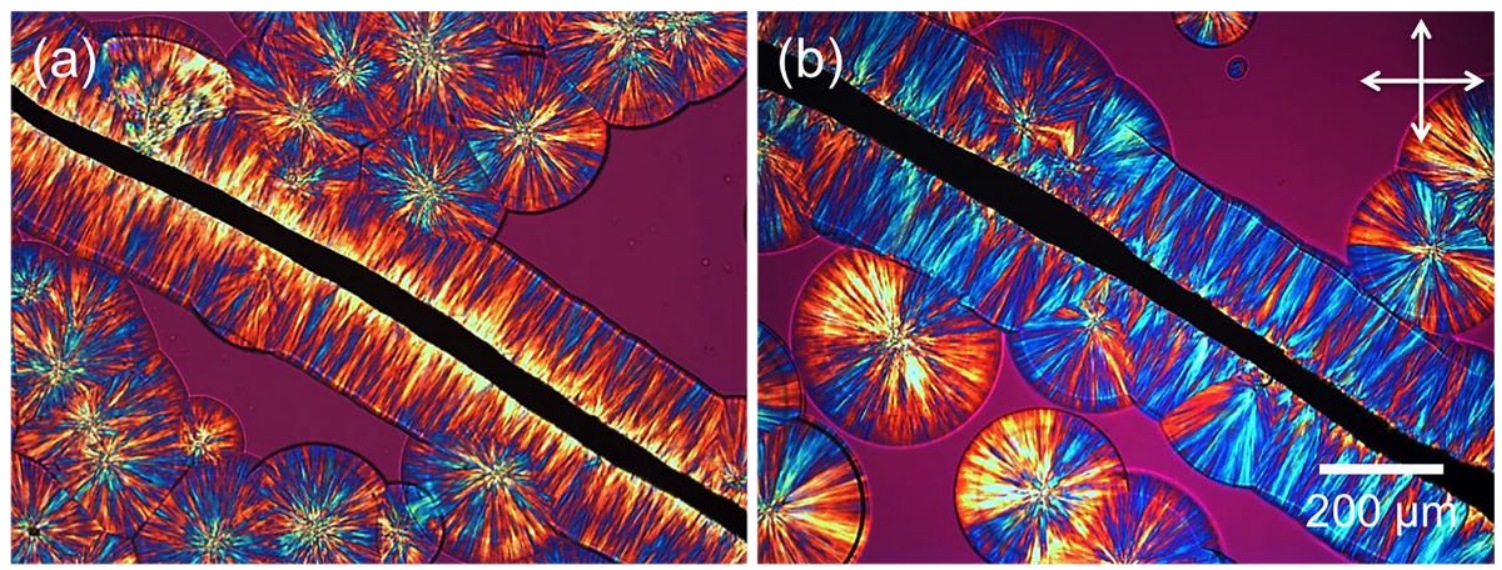

Fig. 2. Optical micrographs of single fiber/iPP composites with a retardation plate. (a) Nanotube fiber composite crystallized at $132{ }^{\circ} \mathrm{C}$ for $20 \mathrm{~min}$, and (b) graphene fiber composite crystallized at $124^{\circ} \mathrm{C}$ for $5 \mathrm{~min}$. Crossed arrows represent crossed polarizers.

The interfacial structure and morphology of iPP surrounding the nanocarbon fibers were found to be strongly dependent on the thermal history. Fig.s $3 a$ and $b$ illustrate the formation of iPP transcrystals of the specimens that were crystallized at $130{ }^{\circ} \mathrm{C}$ for 30 min and then heated to $160{ }^{\circ} \mathrm{C}$. Interestingly, the well-aligned transcrystals surrounding 
the nanotube fiber exhibit solely negative birefringence (Fig. 3a), whereas the pooraligned transcrystals surrounding the graphene fiber show dominant negative birefringence (Fig. 3b). It is believed that the polymer chains undergo a reorientation process at the elevated temperature and thereafter they become mainly parallel to the long axis of nanocarbon fibers due to the strong interactions between iPP and fibers.[30] As a result, the radial lamellae are predominant in the transcrystals that demonstrate negative birefringence under the optical microscope.[41] Fig.s $3 \mathrm{c}$ and d show the structure and morphology of transcrystals of the specimens that were crystallized at $132{ }^{\circ} \mathrm{C}$ for $10 \mathrm{~min}$ and subsequently quenched to room temperature. Remarkably, the transcrystals form double-layered microstructures surrounding both nanotube and graphene fibers. Interestingly, the inner layer is dominated by the negative birefringence transcrystals while the outer layer is dominated by the positive birefringence transcrystals. In situ observation of polymer transcrystallization confirmed that the outer layer microstructures with positive birefringence developed during the quenching process of the specimens after isothermal crystallization at $132{ }^{\circ} \mathrm{C}$. It is believed that during the fast cooling the tangential lamellae nucleate onto the inner transcrystals.[42] As a result, a large amount of the tangential lamellae are formed in the outer layer. These prevalent tangential lamellae illustrate positive birefringence under the optical microscope. 


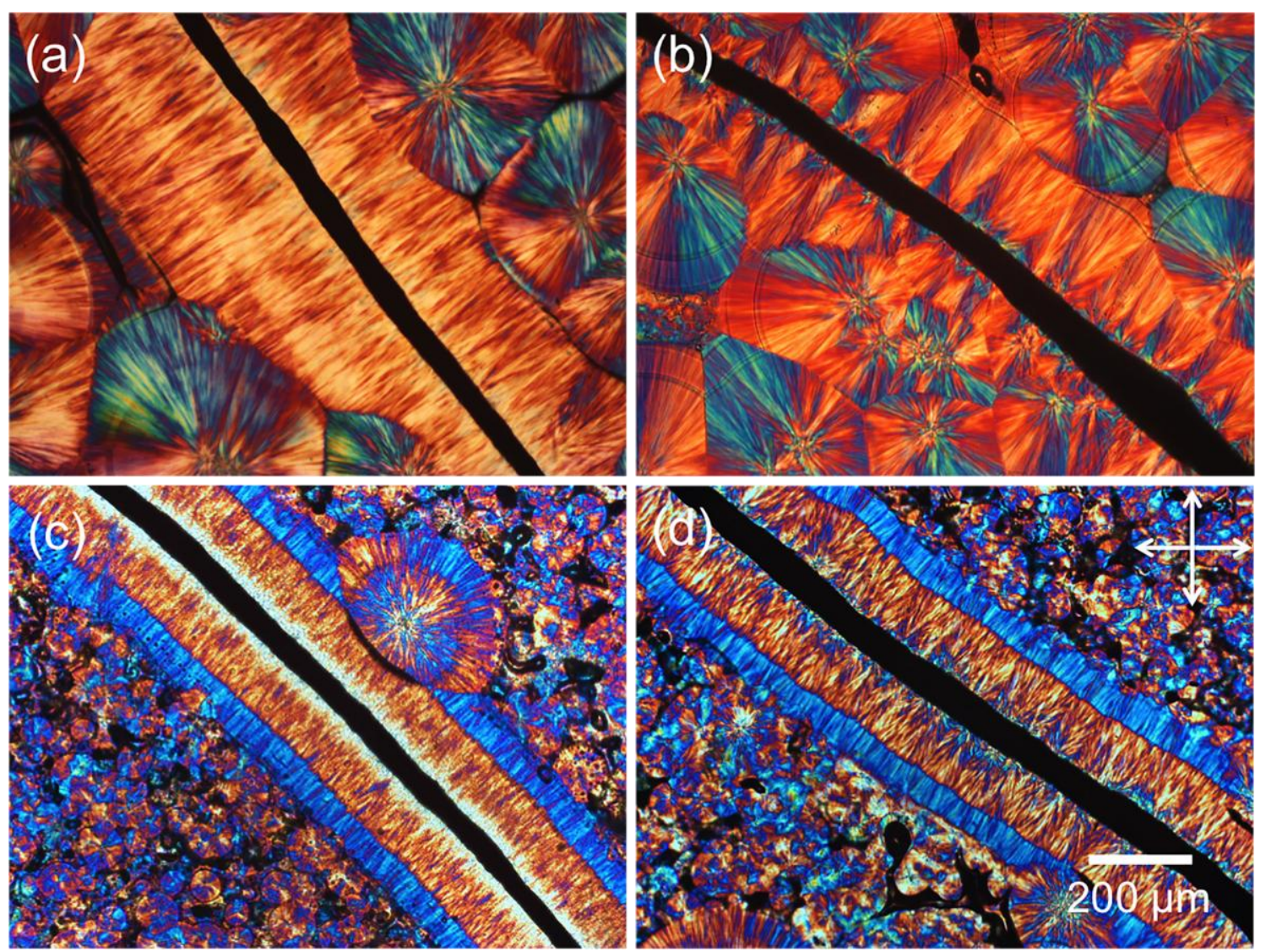

Fig. 3. Optical micrographs of single fiber/iPP composites in the presence of a retardation plate with different heat treatment. (a) and (c) are nanotube fiber composites, while (b) and (d) are graphene fiber composites. (a) and (b) are samples that were crystallized at $130{ }^{\circ} \mathrm{C}$ for $30 \mathrm{~min}$ and then heated to $160{ }^{\circ} \mathrm{C}$. (c) and (d) are samples that were crystallized at $132{ }^{\circ} \mathrm{C}$ for $10 \mathrm{~min}$ and then quenched to room temperature. Crossed arrows represent crossed polarizers.

To visualize the lamellar structures of transcrystals under electron microscope, the transcrystallized specimens were chemically etched to remove the amorphous materials using the mixed acids.[30] Fig. 4 shows the typical SEM images of the transcrystallized specimens after the acid treatment. Transcrystals surrounding the fibers and spherulites away from the fibers are apparent in both nanotube and graphene fiber composites. As expected, the lamellae in the transcrystalline layer are oriented perpendicular to the fibers while the lamellae in the bulk spherulites are organized into the hedgehog-like patterns. Moreover, the transcrystalline lamellae surrounding the nanotube fiber (Fig. 4a) show 
better alignment than those surrounding the graphene fiber (Fig. 4b). Clearly, the radial lamellae of transcrystals surrounding the nanotube fiber are predominant (Fig. 4a), whereas the tangential lamellae of transcrystals surrounding the graphene fiber are prevalent (Fig. 4b). This observation is consistent with our optical microscopic data.
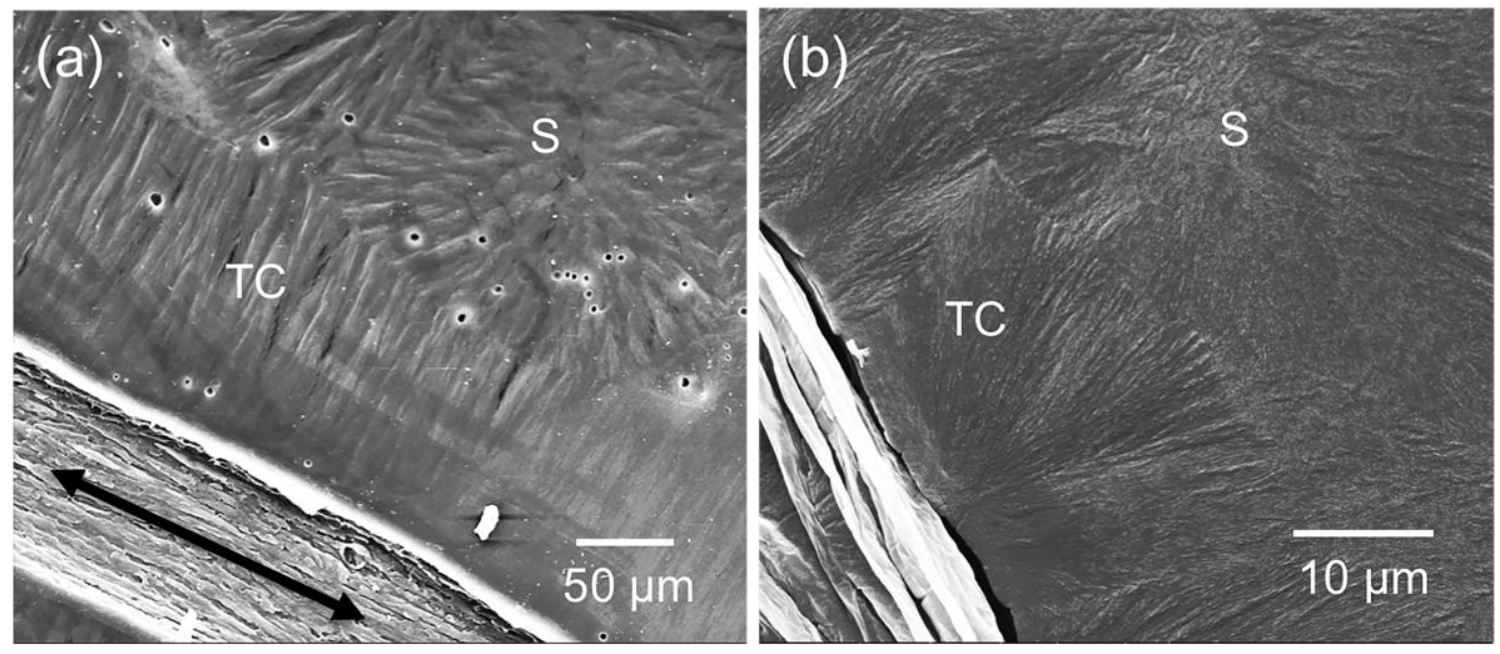

Fig. 4. SEM images of transcrystallized iPP induced by the nanocarbon fibers. (a) nanotube fiber composite etched for $4 \mathrm{~h}$ and (b) graphene fiber composite etched for $2 \mathrm{~h}$. $\mathrm{S}$ denotes spherulites and TC denotes transcrystals. The black arrow in (a) shows the location of the nanotube fiber removed due to long time chemical etching.

To understand the physical origin of interfacial crystallization of the polymers induced by nanotube and graphene fibers, the dynamic process of iPP transcrystallization has been studied using in situ optical microscope. Fig. 5 shows series of optical images of dynamic crystallization of iPP surrounding a single nanotube fiber at $132{ }^{\circ} \mathrm{C}$. It is found that iPP nucleation first occurred at the surface of the nanotube fiber, which is evidenced by the bright crystalline layer at the fiber surface formed within one minute (Fig. 5b). This uniform transcrystalline growth front displays solely negative birefringence, indicating that the nanotube fiber possesses a very high nucleating capacity to induce iPP transcrystallization and the polymer chains are oriented parallel to the long axis of the 
nanotube fiber.[29] With increasing crystallization time, iPP transcrystals grew perpendicular to the long axis of the nanotube fiber (Fig.s 5c-f) and some positive birefringence transcrystals started to appear when far away from the fiber as shown in Fig. 5f. On contrary, the nuclei of the spherulites only developed in the iPP matrix after the heterogeneous nucleation of transcrystals (Fig. 5c) and they subsequently grew into the bulk spherulites with crystallization time (Fig.s 5d-f). Finally, the growth of transcrystals was interrupted by the impingement with the bulk spherulites (Fig. 5f).

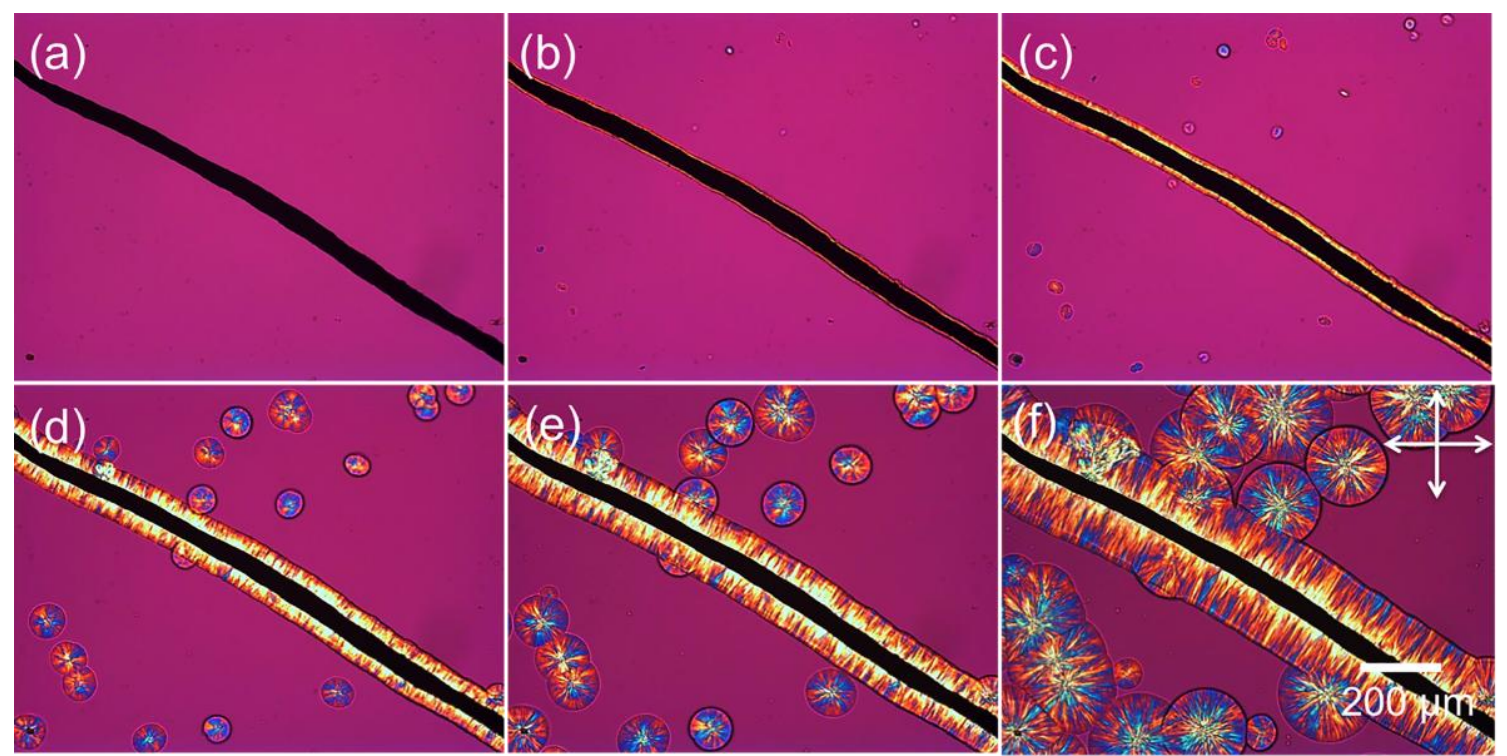

Fig. 5. Series of optical micrographs with a retardation plate of iPP transcrystallization evolution surrounding a single carbon nanotube fiber at $132{ }^{\circ} \mathrm{C}$ with different crystallization time. (a) 0, (b) 1, (c) 2, (d) 5, (e) 8, and (f) $15 \mathrm{~min}$.

Fig. 6 displays series of optical images of iPP transcrystallization surrounding a single graphene fiber at $124^{\circ} \mathrm{C}$. Again, iPP nucleation first occurred at the surface of the graphene fiber (Fig. 6b), which was followed by later formation of the nuclei of spherulites in the iPP matrix (Fig. 6c). On contrary to the nanotube fiber, the transcrystalline growth front at the surface of the graphene fiber is not uniform and it exhibits mixed birefringence as shown in Fig. 6b. This observation implies that the 
graphene fiber has lower nucleating capacity for iPP transcrystallization as compared to the nanotube fiber. As a result, the polymer chains are oriented not solely parallel to the long axis of the graphene fiber and the tangential lamellae are dominant (Fig.s 6d-f).

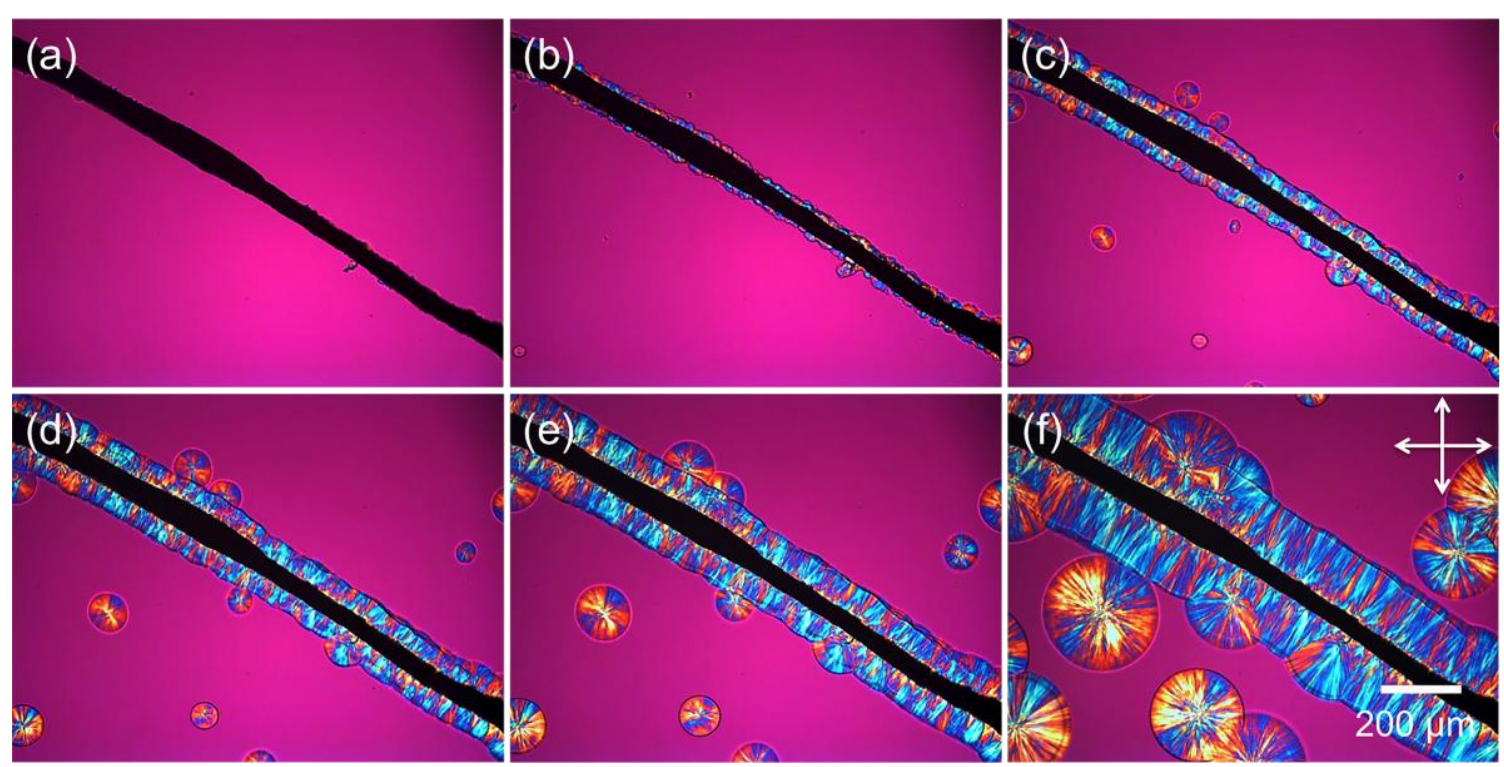

Fig. 6. Series of optical micrographs with a retardation plate of iPP transcrystallization evolution surrounding a single graphene fiber at $124^{\circ} \mathrm{C}$ with different crystallization time. (a) 0 , (b) 0.3 , (c) 1.0, (d) 1.5 , (e) 2.0 , and (f) $4.0 \mathrm{~min}$.

To study the kinetics of interfacial crystallization of iPP surrounding the nanocarbon fibers, video microscopy was utilized to record the isothermal growth of iPP transcrystals at different crystallization temperatures. The thickness of transcrystalline layers was analyzed using ImageJ. Fig.s 7a and b show the growth of iPP transcrystals over time in the presence of nanotube and graphene fibers at various crystallization temperatures. The specimens containing both nanotube and graphene fibers demonstrate a linear relationship between the thickness of transcrystalline layers and crystallization time over the entire temperature range. To this end, the growth rate $(G)$ of transcrystals at each temperature can be derived from the slope of the plot. It is evidenced that reducing temperature accelerates iPP nucleation with less induction time and therefore promotes 
iPP transcrystallization with a higher growth rate. At the same crystallization temperature, the growth rate of transcrystals is faster in the nanotube fiber composites than that in the graphene fiber composite.

(a)

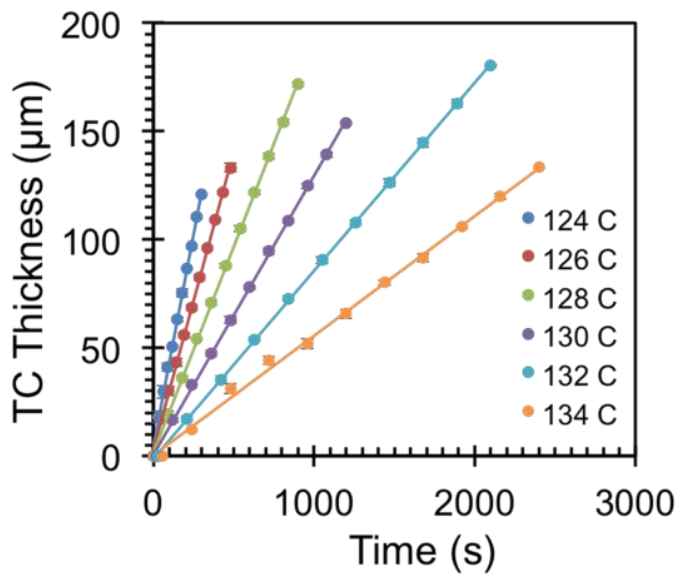

(c)

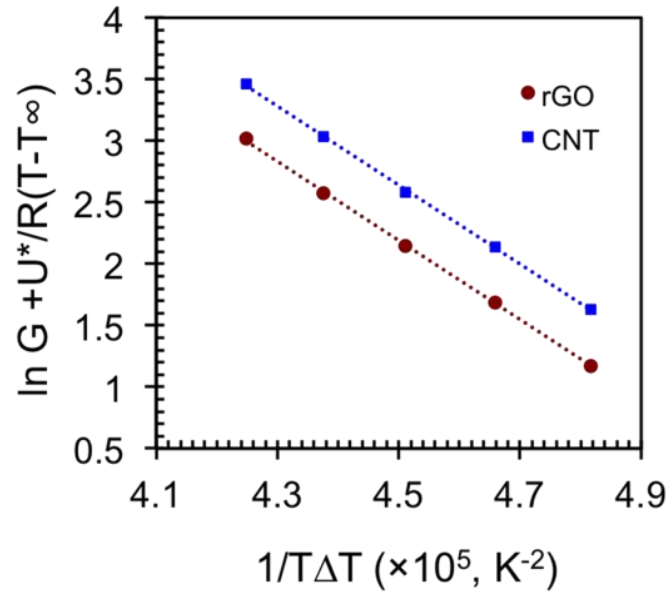

(b)

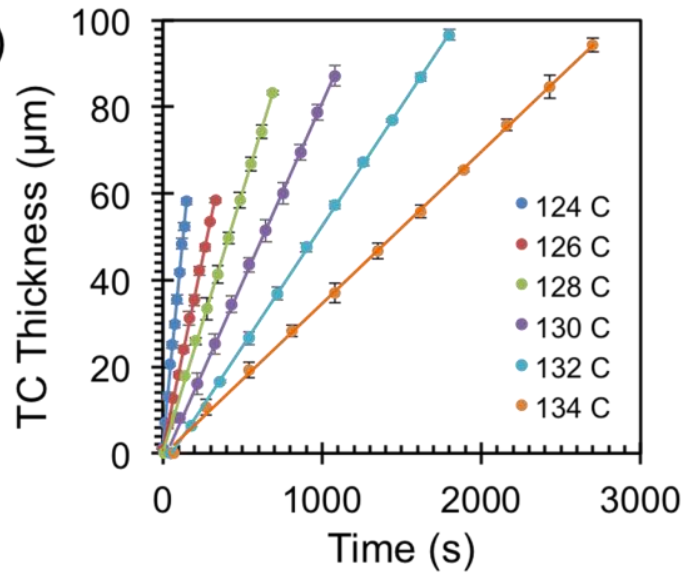

(d)

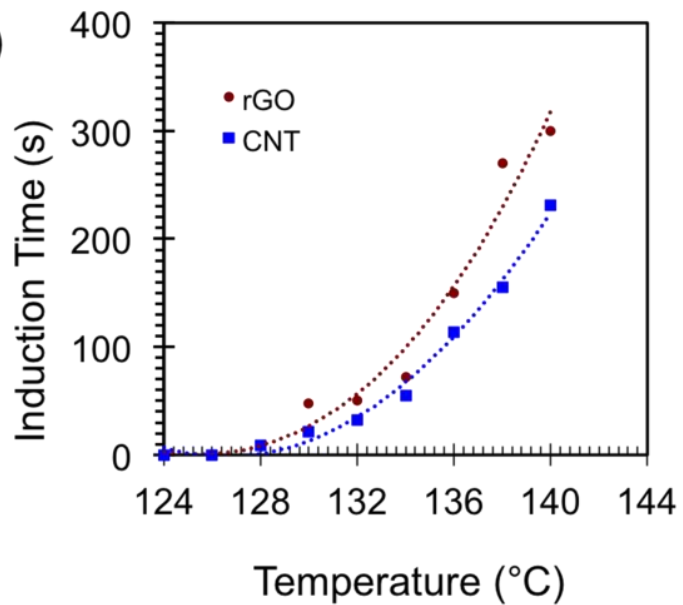

Fig. 7. Kinetics of iPP transcrystallization induced by nanocarbon fibers at different temperatures. (a) The plots of the thickness of transcrystals (TCs) versus time in the nanotube fiber/iPP composite, (b) the plots of the thickness of transcrystals versus time in the graphene fiber/iPP composite, (c) the plots of growth rate $\left(\ln G+U * / R\left(T-T_{\infty}\right)\right.$ versus temperature $(1 / T \Delta T)$, and (d) the plots of induction time versus crystallization temperature. $\Delta T=T_{m}^{0}-T$, where $T_{m}^{0}$ is the melting temperature at equilibrium.

On the base of the Hoffman-Lauritzen theory,[43] the growth rate $(G)$ of polymer crystals is expressed by eq. 1

$$
G=G_{0} \exp \left(\frac{-U^{*}}{R\left(T-T_{\infty}\right)}\right) \exp \left(\frac{-K_{g}}{T\left(T_{m}^{0}-T\right)}\right)
$$


where $G_{0}$ is the temperature-independent constant, $U^{*}$ denotes the activation energy of polymer chain motion in the melt, $R$ is the universal gas constant, $T_{\infty}$ represents the theoretical temperature at which the polymer chain motion associated with the viscous flow terminates, $T_{m}^{0}$ is the melting temperature at equilibrium, and $K_{g}$ stands for the nucleation parameter. The nucleation parameter $\left(K_{g}\right)$ describes the probability that a nucleus reaches the critical size for crystallization and it is further expressed by eq. 2

$$
K_{g}=\frac{4 b_{0} \sigma \sigma_{e} T_{m}^{0}}{k_{B} \Delta h_{f}}
$$

where $b_{0}$ represents the thickness of the new monolayer in the crystals, $\sigma$ is the lateral surface free energy, $\sigma_{e}$ is the fold surface free energy, $k_{B}$ is the Boltzmann constant, and $\Delta h_{f}$ denotes the enthalpy of fusion per unit volume. There are two exponential terms in eq. 1. The first term describes the diffusion process of the polymer chains in melt, whereas the second one addresses the thermodynamic driving force of chain-folding. To this end, the eq. 1 is replaced by eq. 3

$$
\ln G+\frac{U^{*}}{R\left(T-T_{\infty}\right)}=-\frac{K_{g}}{T \Delta T}+\ln G_{0}
$$

Fig. 7c illustrates the plots of $\ln G+\frac{U^{*}}{R\left(T-T_{\infty}\right)}$ versus $1 / T\left(T_{m}^{0}-T\right)$ for both nanotube and graphene fiber composites. The best-fit straight lines are apparent for both. From the slope of each straight line, the $K_{g}$ was estimated to be $3.205 \times 10^{5} \mathrm{~K}^{2}$ and $3.208 \times 10^{5} \mathrm{~K}^{2}$ for nanotube and graphene induced iPP transcrystallization, respectively. For $\alpha$-form crystals of iPP, it is reported that $b$ is $6.26 \AA, \sigma=1.10 \times 10^{-2} \mathrm{~J} / \mathrm{m}^{2}, T_{m}^{0}=458 \mathrm{~K}$, and $\Delta h_{f}$ $=209 \mathrm{~J} / \mathrm{g}$.[44] From these known values and $K_{g}$, the fold surface free energy $\sigma_{e}$ of iPP transcrystals was calculated to be $6.932 \times 10^{-2} \mathrm{~J} / \mathrm{m}^{2}$ and $6.938 \times 10^{-2} \mathrm{~J} / \mathrm{m}^{2}$ in the nanotube and graphene fiber composites, respectively. These $\sigma_{e}$ values are nearly identical and 
they are in good agreement with the literature reports on iPP transcrystals induced by nanocarbon fibers $\left(5.4-7.6 \times 10^{-2} \mathrm{~J} / \mathrm{m}^{2}\right)[29-31]$ and carbon fibers $\left(4-11 \times 10^{-2} \mathrm{~J} / \mathrm{m}^{2}\right)$.[40] Our observation suggests that nanocarbon fibers have little effects on the growth kinetics of iPP transcrystallization once the nucleation step is completed.

Fig. $7 \mathrm{~d}$ shows the plots of induction time versus crystallization temperature. With increasing crystallization temperature, the induction time increases for both nanotube and graphene fiber composites. Significantly, the inductions time in the nanotube fiber composite is much shorter than that in the graphene fiber under the same condition, indicating that the nanotube fiber possesses more favorable nucleation sites for accelerating iPP transcrystallization than the graphene fiber.[31]

To test the physical properties of transcrystals, the specimens were prepared by quenching the single fiber composites from high isothermal crystallization temperature to room temperature. The resulting double-layered transcrystals were then heated stepwise until the transcrystals were completely melted. Fig. 8 shows in situ optical microscopic observations on melting of iPP transcrystals in the single nanotube fiber composite. As expected, as-prepared specimen displays double-layered transcrystals that are composed of a negative birefringence inner layer and a positive birefringence outer layer (Fig. 8a). Interestingly, when the sample was heated up to $155^{\circ} \mathrm{C}$, the outer layer of transcrystals changed from positive birefringence into mixed birefringence (Fig. 8b), implying that the large amount of the tangential lamellae transform into the radial lamellae.[30] When the sample was heated up to $170{ }^{\circ} \mathrm{C}$, the outer layer of transcrystals became bright negative birefringence (Fig.s 8c and d), indicating the predominant radial lamellae formed in the outer layer. Further increasing the temperature up to $180^{\circ} \mathrm{C}$, both bulk spherulites and 
outer layer of transcrystals melt immediately (Fig. 8e) while the inner layer of transcrystals is resistant to melt for $45 \mathrm{~s}$ (Fig. 8f). This phenomenon indicates that the highly ordered inner layer transcrystals possess higher thermal stability.[21] The parallel experiments were conducted for the graphene fiber/iPP composites. Unfortunately, we could not recognize the selective melting of transcrystals. This failure may be attributed to the less ordered transcrystals induced by the graphene fibers.
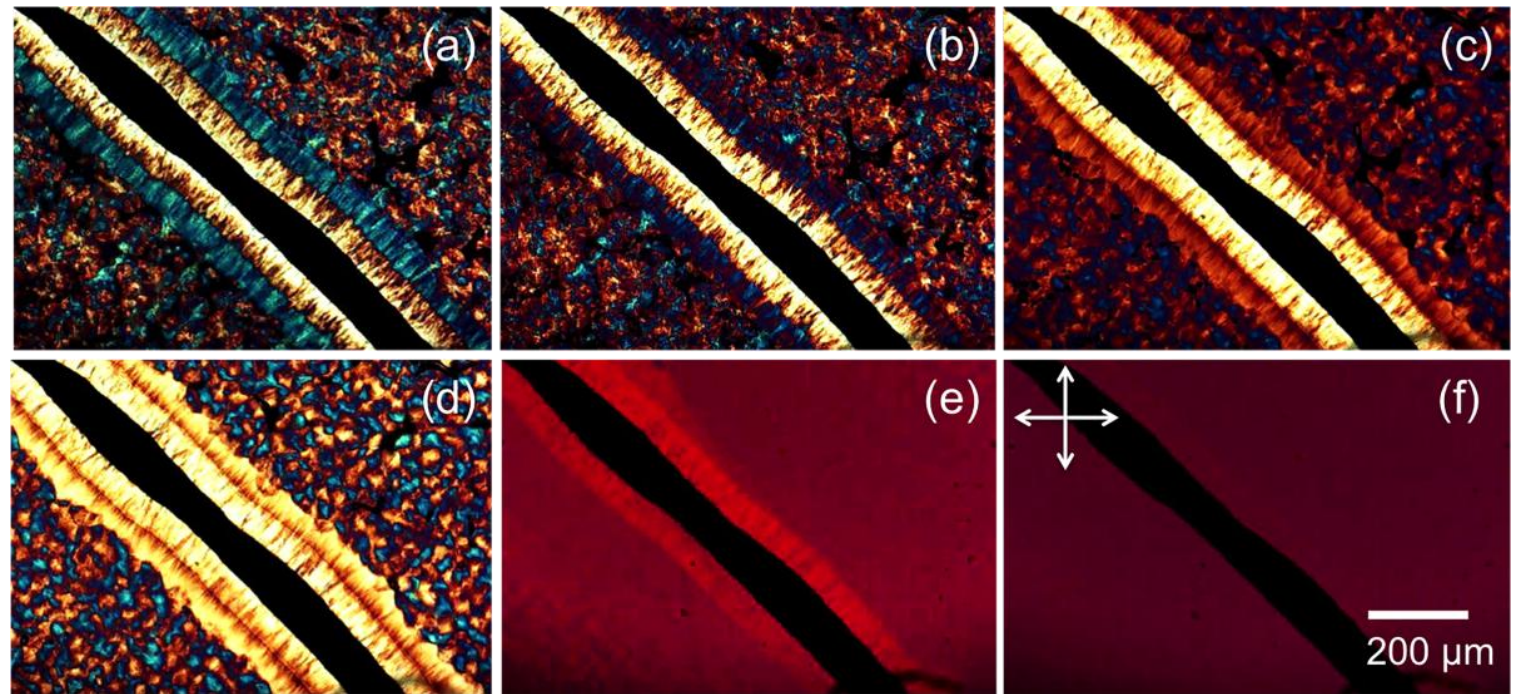

Fig. 8. In situ optical microscopic observation of melting of transcrystals with the retardation plate in a single nanotube fiber composite during heating. The specimen was isothermally crystallized at $130{ }^{\circ} \mathrm{C}$ for $20 \mathrm{~min}$ and subsequently quenched to room temperature. As-prepared specimen was then heated stepwise to different high temperatures. (a) room temperature, (b) $155^{\circ} \mathrm{C}$, (c) $160^{\circ} \mathrm{C}$, (d) $170{ }^{\circ} \mathrm{C}$, (e) $180{ }^{\circ} \mathrm{C}$ for $0 \mathrm{~s}$, and (f) $180{ }^{\circ} \mathrm{C}$ for $45 \mathrm{~s}$. Crossed arrows represent crossed polarizers.

\subsection{Polymorphism}

The iPP exhibits only $\alpha$-form crystals in the bulk under the normal processing conditions.

It has been reported that adding nanotubes or graphene can induce polymorphous crystals that are otherwise impossible for iPP host under the same conditions.[29,30] To understand the nanocarbon induced polymorphism of iPP transcrystals, in situ optical microscopy and X-ray diffraction techniques were employed. Remarkably, the formation 
of $\beta$-form iPP in the transcrystalline layer often occurred in the nanotube and graphene fiber composites. Moreover, the amount of $\beta$-form transcrystals of iPP induced by the nanotube fiber is much higher than that by the graphene fiber.

Fig. 9 shows the optical micrographs of $\beta$-form transcrystals of iPP induced by nanotube and graphene fibers at $132{ }^{\circ} \mathrm{C}$. It is shown that some fan-shaped domains appear in the transcrystalline layers that exhibit much stronger birefringence as compared to the rest of the transcrystalline interphase. These bright fan-shaped domains are identified as $\beta$-form transcrystals of iPP based on the literature report.[45]
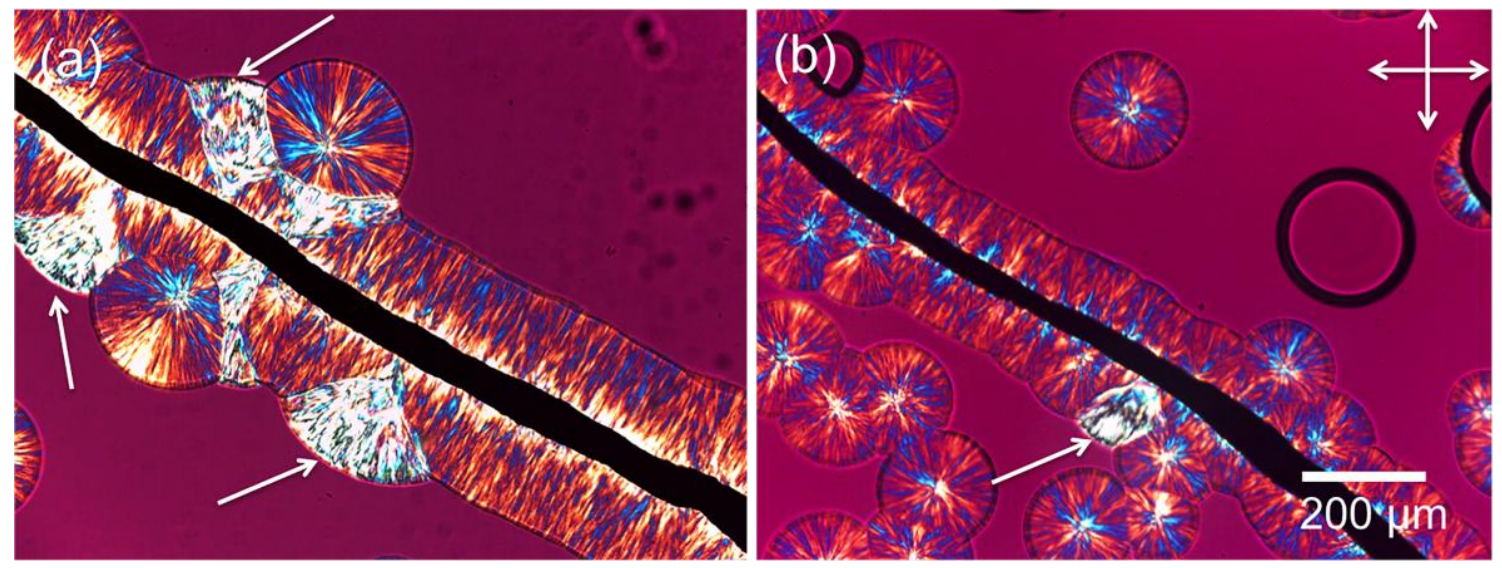

Fig. 9. Typical optical micrographs of polymorphous transcrystals of iPP induced by the nanocarbon fibers at $132{ }^{\circ} \mathrm{C}$. (a) nanotube fiber composite and (b) graphene fiber composite. Arrows show $\beta$-form transcrystals. Crossed arrows represent crossed polarizers.

Fig. 10 shows in situ optical microscopic study on the morphology evolution of $\beta$-form transcrystals of iPP during heating. As-prepared specimen possesses both $\alpha$ - and $\beta$-form iPP in the transcrystalline layer (Fig. 10a). When the specimen was heated up to $155^{\circ} \mathrm{C}$, the optical birefringence of iPP crystals including $\alpha$ - and $\beta$-form transcrystals increased greatly (Fig. 10b). Significantly, the mixed birefringence transcrystals becomes negative birefringence and thus the radial lamellae are predominant over the tangential lamellae. 
When the specimen was further heated up to the melting point of $\beta$ - form crystals of iPP that is around $160^{\circ} \mathrm{C}$, the fan-shaped domains disappeared immediately but the rest of transcrystals of iPP remained unchanged (Fig.s $10 \mathrm{c}$ and d). This selective melting behavior of the fan-shaped domains in the transcrystalline layer clearly confirmed the formation of $\beta$ - form transcrystals of iPP.[46] The parallel experiments were done for the graphene fiber/iPP composites and the similar selective melting behavior of fan-shaped $\beta$ - form transcrystals of iPP was observed.
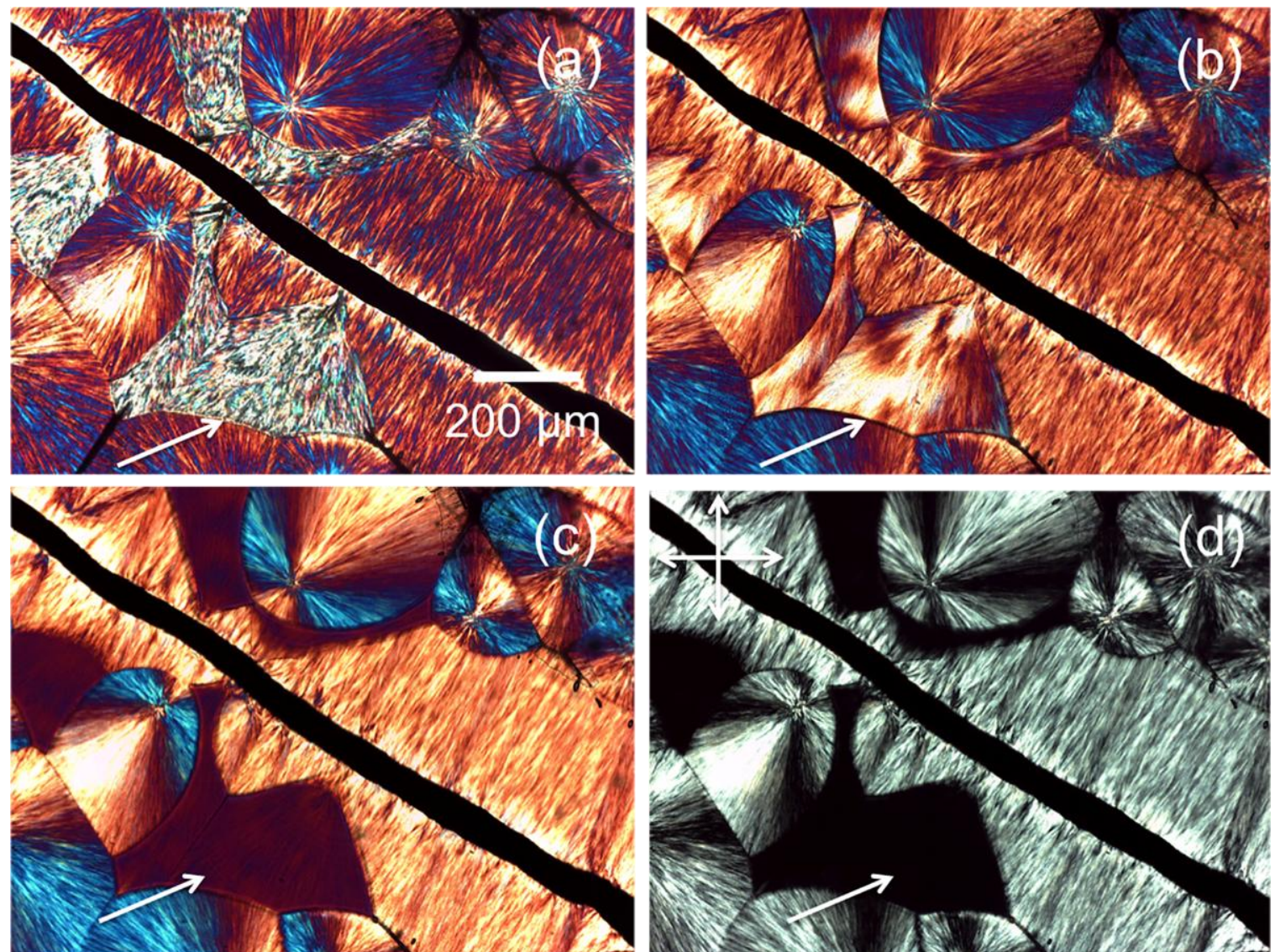

Fig. 10. Series of optical micrographs of polymorphous transcrystals of iPP with the retardation plate induced by the nanotube fiber. The specimen was crystallized at $132{ }^{\circ} \mathrm{C}$ for $30 \mathrm{~min}$ and then cooled down to room temperature. As-prepared specimen was subsequently heated stepwise to different temperatures. (a) as-prepared specimen at room temperature, (b) $155^{\circ} \mathrm{C}$, (c) $160^{\circ} \mathrm{C}$, and (d) the same as (c) but without the retardation plate. Arrows show $\beta$ - form transcrystals. Crossed arrows represent crossed polarizers. 
The formation of $\beta$-form transcrystals of iPP was further verified by X-ray diffraction. Fig. 11 shows X-ray diffraction data of iPP transcrystals induced by the nanotube fiber at $132{ }^{\circ} \mathrm{C}$. The 2D WAXD pattern (Fig. 11a) displays that the intensities of rings are not circumferentially uniform, which is indicative of certain degree of preferred orientation of the polymer chains with respect to the fiber axis in the transcrystals.[29] The chain axis orientation parallel to the CNTs has been observed in the crystallization of various polymers on similar CNT fibers.[33] The 1D WAXD curve illustrates the main diffraction peaks of the radial scan located at $2 \theta=14.2,17.0,18.7,21.2$ and $22.0^{\circ}$ (Fig. 11b). These peaks are, respectively, indexed as (110), (040), (130), (111) and (041) reflections according to $\alpha$-form monoclinic packing of iPP.[29] Significantly, there is additional strong reflection at $2 \theta=16.1^{\circ}$, which is indexed as (300) reflection according to $\beta$-form hexagonal packing of iPP[37] (Fig. 11b). The parallel experiments were performed for the graphene fiber/iPP composites. However, the amount of $\beta$-form transcrystals of iPP and orientation of polymer chains in the graphene fiber composites were significantly reduced (SI-Fig. 1). The presence of $\beta$-form transcrystals of iPP induced by nanocarbons is very interesting, as they are unstable under the normal processing conditions. It has been well recognized that $\beta$-form crystals of iPP have outstanding impact strength and toughness.[37,47] To produce high performance iPP materials, it is often guided to add $\beta$-form nucleation agents into iPP products.[47] Our work suggests that nanotubes and graphene serve as $\beta$-form nucleation agents under the certain conditions to promote $\beta$-form crystallization of iPP. 

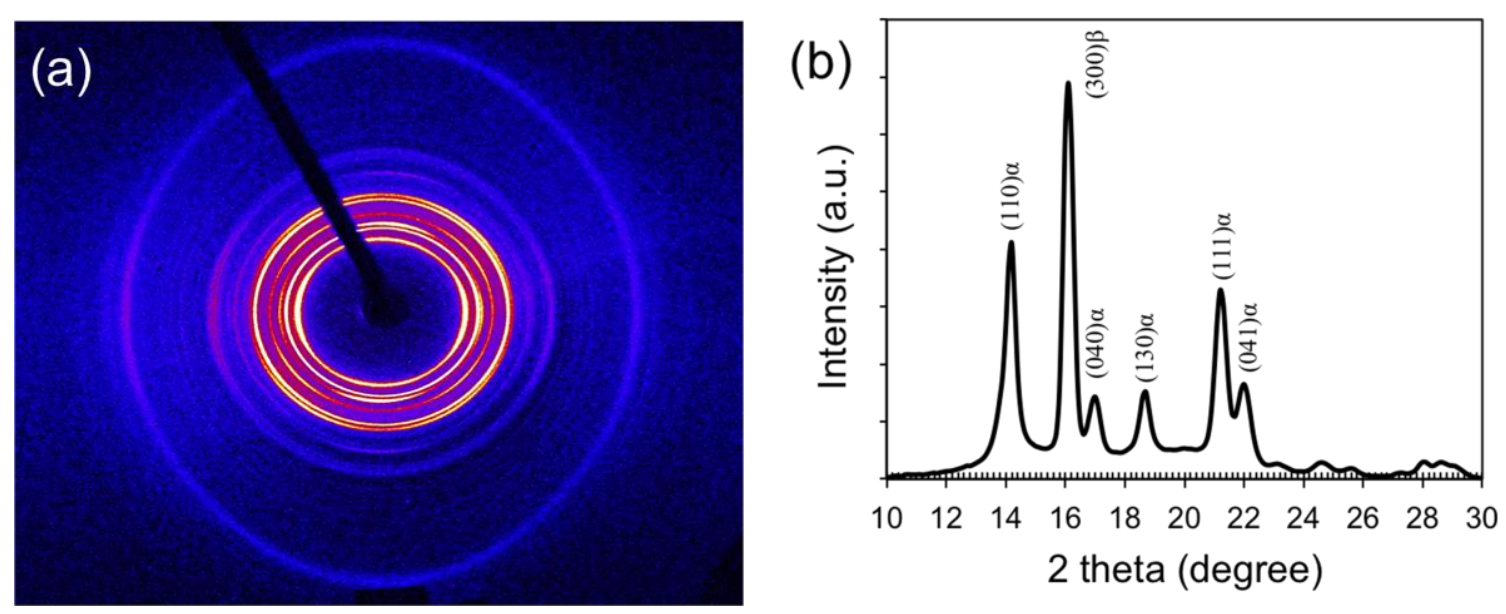

Fig. 11. Wide-angle X-ray diffractions of polymorphous transcrystalline layers of iPP induced by the nanotube fiber. (a) 2D WAXD pattern and (b) 1D WAXD data of integrated radial scan.

\subsection{Mechanism}

While both carbon nanotubes and graphene fibers can accelerate iPP transcrystallization and promote the $\beta$-form transcrystals, they behave differently in certain ways. Our observations demonstrate that the nanotube fibers have much higher nucleation ability to effectively induce iPP transcrystallization and polymorphism than the graphene fibers. In general, polymer transcrystallization in the presence of the fibers is a complex process and the formation mechanism has not been fully understood.[40] Many factors can affect the formation of polymer transcrystallization, including topography of the fiber, thermal conductivity of the fiber, interfacial interaction, and so on. In our work, at least these three factors play important roles in controlling polymer crystallization.

First, both nanotube and graphene fibers have rough surfaces evidenced by the groovelike microstructures as shown in Fig. 1. Significantly, the nanotube fibers show nanoscale grooves (Fig.s 1a and b) while the graphene fiber display microscale grooves (Fig.s 1c and d). It has been reported that groove-like microstructures of the fibers have greatly facilitated the parallel orientation of polymer chains along the grooves, leading to the 
lateral formation of stable nuclei of transcrystals.[48] As the nano-grooves of the nanotube fiber has much larger specific surface areas than the micro-grooves of the graphene fiber, the higher density nucleation sites of transcrystals are generated on the nanotube fibers than those on the graphene fibers. This interpretation is supported by our in situ optical microscopic observations of the negative birefringence nucleation layer on the nanotube fibers (Fig. 5b) and the positive birefringence nucleation layer on the graphene fibers (Fig. 6b).

Second, the carbon nanotubes were used without any chemical treatments and therefore, the nanotube fibers possess very high thermal conductivity. On contrary, the graphene fibers were made from the graphene oxide fibers using chemical reduction and the graphene oxide sheets were produced from the natural graphite flakes using the strong oxidizing agents. As a result, there are abundant structural defects and functional groups on the graphene oxide sheets.[49] Furthermore, the chemical reduction is far less than $100 \%$ efficient in producing a purely $\mathrm{sp}^{2}$-bonded graphitic structure.[50] Thus, the remaining defects in the graphene fibers used in this work lead to a low thermal conductivity of the fiber. It has been well recognized that the mismatch of the thermal conductivity between the polymer matrix and fibers promotes the formation of the transcrystals.[51] When the fiber/polymer composites are cooled from melt to the crystallization temperature, the fast heat transport of the fiber allows the fiber to reach the crystallization temperature much earlier than the polymer host. As a result, there is a temperature gradient in the fiber composite in which the fiber surface has a lower temperature than the polymer host. When the temperature gradient at the fiber-polymer interface is larger than the critical condition, the nucleation will occur first on the fiber 
surface.[51] In our work, the temperature gradient at the nanotube-iPP interfaces is larger than that at the graphene-iPP interfaces. Therefore, the nanotube fibers promote iPP transcrystallization much earlier than the graphene fibers, which is evidenced by the shorter induction time of the nanotube fibers as shown in Figure 7d.

Third, it has been recognized that there are $\mathrm{CH}-\pi$ interactions between the polymer chains of iPP and the crystalline graphite surfaces of nanotubes and graphene that accelerate polymer crystallization.[52] While the strict epitaxial relationship between the iPP chains and nanocarbons in terms of lattice matching is not a prerequisite for transcrystallization, the wettability of the polymer on the nanocarbon fiber surface is a major factor for stimulating the polymer-fiber interactions that accelerate the heterogeneous nucleation.[33] The wetting condition is determined by the wetting coefficient $\omega_{a d},[53]$

$$
\omega_{a d}=\frac{\sigma_{F P}-\sigma_{F}}{\sigma_{P}}
$$

where $\sigma_{F P}, \sigma_{F}$ and $\sigma_{P}$ are the fiber-polymer interfacial energy, the surface energy of the fiber and the surface energy of the polymer, respectively. When $\omega_{a d}=-1$, the fiber is completely wetted by the polymer. When $-1<\omega_{a d}<0$, the fiber is partially wetted.[53] The fiber-polymer interfacial energy is estimated by

$$
\sigma_{F P}=\sigma_{F}+\sigma_{P}-2\left(\sqrt{\sigma_{F}^{d} \sigma_{P}^{d}}+\sqrt{\sigma_{F}^{p} \sigma_{P}^{p}}\right)
$$

where $\sigma^{d}$ and $\sigma^{p}$ are, respectively, disperse and polar components of the surface energy. The literature data for the surface energy components of iPP, nanotubes and reduced graphene oxide is summarized in Table 1. Based on these known values, the wetting coefficient $\omega_{a d}$ was calculated to be -0.63 and -0.60 for the nanotube-iPP and graphene- 
iPP interfaces, respectively. As the graphene oxide fibers are not completely reduced to produce the graphene fibers and there are structural defects on the graphene fiber surface,[49] the actual value of $\omega_{a d}$ for the graphene-iPP interface will be less negative than -0.60 . Therefore, the wettability of iPP on the nanotube fiber is higher than that on the graphene fiber.

Table 1. Surface energy components of iPP, nanotubes, and reduced graphene oxide

\begin{tabular}{|c|c|c|c|c|}
\hline & $\sigma\left(\mathrm{mJ} / \mathrm{m}^{2}\right)$ & $\sigma^{d}\left(\mathrm{~mJ} / \mathrm{m}^{2}\right)$ & $\sigma^{p}\left(\mathrm{~mJ} / \mathrm{m}^{2}\right)$ & $\omega_{a d}$ \\
\hline iPP[54] & 31.7 & 31.1 & 0.6 & --- \\
\hline Carbon nanotubes[55] & 27.8 & 17.6 & 10.2 & -0.63 \\
\hline Reduced graphene oxide[56] & 28.2 & 16.5 & 11.7 & -0.60 \\
\hline
\end{tabular}

Based on the experimental data and our analysis, Scheme 1 highlights the schematic representation of iPP transcrystallization at the presence of carbon nanotube and graphene fibers. The nanotube fiber promotes high-density heterogeneous nucleation sites that force the lamellae to solely grow perpendicular to the fiber (Scheme 1a). As a result, the radial lamellae develop in which the polymer chains are parallel to the long axis of the fiber. On contrary, the graphene fiber can only induce low-density nucleation sites because of its structural defects and weak interfacial interactions (Scheme 1b). In this case, the lateral extension of the lamellae is not hindered by neighboring lamellar crystals and thereof, the lamellae can grow either perpendicular or parallel to the long axis of the fiber. As a result, the tangential lamellae are dominant in the transcrystalline layer. 
(a)

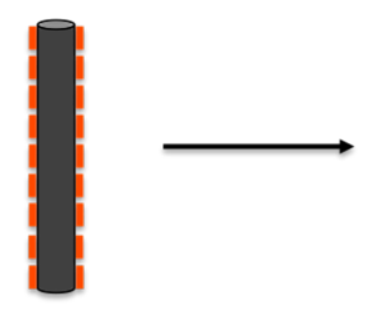

(b)

\section{CNT}

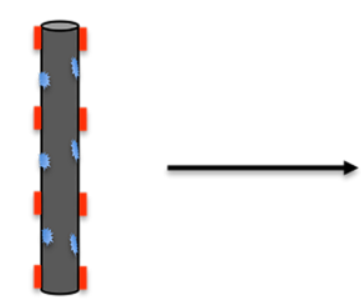

rGO
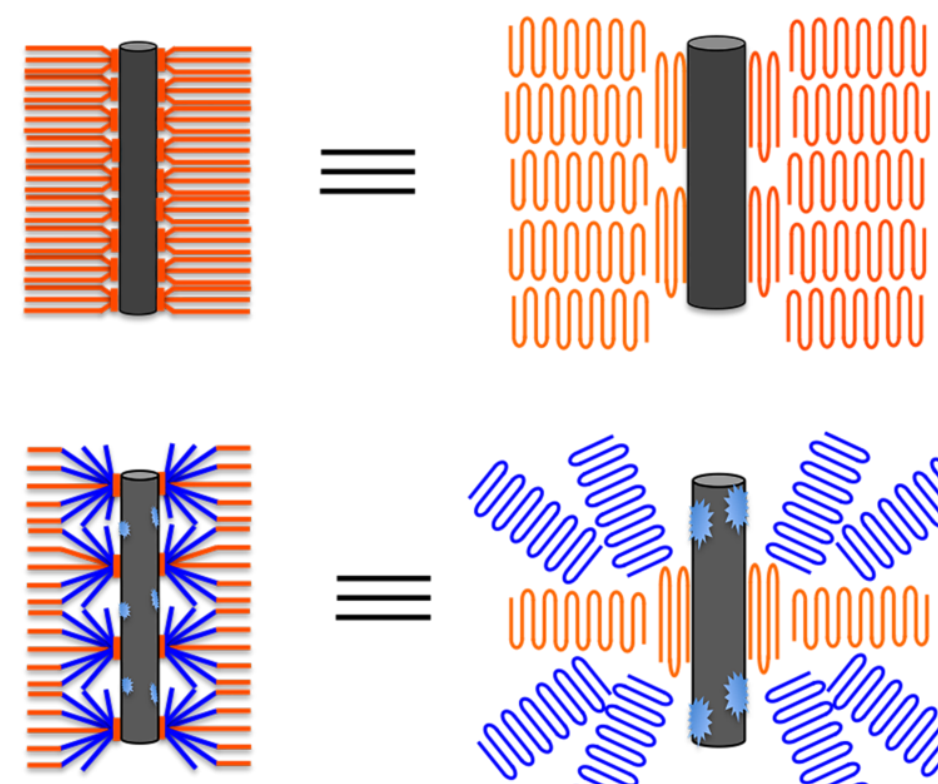

Scheme 1. Schematic representation of polymer transcrystallization induced by nanocarbon fibers. (a) Carbon nanotube fiber composite and (b) graphene fiber composite.

\section{Conclusions}

In summary, we have in situ investigated the comparative study on interfacial crystallization of isotactic polypropylene (iPP) surrounding carbon nanotube and graphene fibers. Both nanotube and graphene fibers act as orientation templates and heterogeneous nucleating agents for accelerating transcrystallization of iPP to grow oriented lamellar crystals perpendicular to the long axis of the fibers. The carbon nanotube fiber promotes the high-density nucleation sites to produce the radial lamellae in the transcrystals. On contrary, the graphene fiber induces the low-density nucleation sites to yield the tangential lamellae because of its structural defects and weak interfacial interactions with iPP. Detailed analysis on transcrystallization kinetics reveals that the fold surface free energy of iPP surrounding both nanotube and graphene fibers are close 
to be $\sim 6.9 \times 10^{-2} \mathrm{~J} / \mathrm{m}^{2}$ while the induction time in the nanotube composites is faster than that in the graphene composites. Ordered iPP transcrystals surrounding the nanotube fiber show higher thermal resistance than that surrounding the graphene fiber. Under appropriate conditions, the $\beta$-form transcrystals of iPP are formed that are more preferable to the nanotube fiber than the graphene fiber. The influence factors in terms of fiber surface morphology, mismatch of thermal conductivity, and interfacial wettability have been addressed to determine the different reinforcement mechanisms between nanotube and graphene fibers.

\section{Acknowledgements}

This work is primarily supported by the Extramural Funding Initiative of Cal Poly. J.P. A and M. R. P. acknowledge research support from the Bill Moore Research Fellowship of Cal Poly. S. Z. acknowledges financial support from the National Science Foundation (CMMI-1345138, CBET-1510207) and American Chemical Society-Petroleum Research Fund (53970-UR7). J.J.V. is grateful for financial support from MINECO (RyC-201415115, Spain) and MAD2D project (S2013/MIT-3007, Comunidad de Madrid). 


\section{Reference}

[1] H. Kim, A.A. Abdala, C.W. MacOsko, Macromolecules. 43 (2010) 6515-6530.

[2] A.K. Geim, Science 324 (2009) 1530-1534.

[3] I.S.I. Web, S. This, H. Press, M., Science 1530 (2014).

[4] M.F.L. De Volder, S.H. Tawfick, R.H. Baughman, A J. Hart, Science 339 (2013) $535-9$.

[5] Z. Spitalsky, D. Tasis, K. Papagelis, C. Galiotis, Prog. Polym. Sci. 35 (2010) $357-$ 401.

[6] X. Sun, H. Sun, H. Li, H. Peng, Adv. Mater. 25 (2013) 5153-5176.

[7] B.A. Newcomb, L.A. Giannuzzi, K.M. Lyons, P. V Gulgunje, K. Gupta, Y. Liu, et al., Carbon N. Y. 93 (2015) 502-514.

[8] B. Arash, Q. Wang, V.K. Varadan, Sci. Rep. 4 (2014) 1-8.

[9] S. Zhang, L. Zhu, C.P. Wong, S. Kumar, Macromol. Rapid Commun. 30 (2009) 1936-1939.

[10] S. Zhang, W. Lin, X. Yu, C. Wong, S.Z.D. Cheng, D.G. Bucknall, Macromol. Chem. Phys. 211 (2010) 1003-1011.

[11] S. Zhang, W. Lin, C.P. Wong, D.G. Bucknall, S. Kumar, ACS Appl. Mater. Interfaces. 2 (2010) 1642-1647.

[12] H.G. Chae, B.A. Newcomb, P. V Gulgunje, Y. Liu, K.K. Gupta, M.G. Kamath, et al., Carbon N. Y. 93 (2015) 81-87.

[13] E.D. Laird, C.Y. Li, 46 (2013) 2877-2891.

[14] A. Alekseev, D. Chen, E.E. Tkalya, M.G. Ghislandi, Y. Syurik, Adv. Funct. Mater. 22 (2012) 1311-1318. 
[15] D. Majumdar, M. Baskey, S.K. Saha, Macromol. Rapid Commun. 32 (2011) $1277-1283$.

[16] Y. Li, Polymer (Guildf). 52 (2011) 2310-2318.

[17] S. Cheng, X. Chen, Y.G. Hsuan, C.Y. Li, Macromolecules. 45 (2012) 993-1000.

[18] H. Jang, H. Kim, J. Nam, J. Suhr, Carbon N. Y. 77 (2014) 390-397.

[19] P. Xu, J. Loomis, R.D. Bradshaw, B. Panchapakesan, Nanotechnology. 23 (2012) $505713(1-7)$.

[20] Y. Liu, S. Kumar, ACS Appl. Mater. Interfaces. 6 (2014) 6069-6087.

[21] C. Chen, B. He, S. Wang, G. Yuan, L. Zhang, Eur. Polym. J. 63 (2015) 177-185.

[22] B.K. Sarker, J. Liu, L. Zhai, S.I. Khondaker, ACS Appl. Mater. Interfaces. 3 (2011) 1180-1185.

[23] N. Behabtu, C.C. Young, D.E. Tsentalovich, O. Kleinerman, X. Wang, A.W.K. Ma, et al., Science 339 (2013) 182-6.

[24] H. Choo, Y. Jung, Y. Jeong, H.C. Kim, B.-C. Ku, Carbon Lett. 13 (2012) 191-204.

[25] W. Lu, M. Zu, J.-H. Byun, B.-S. Kim, T.-W. Chou, Adv. Mater. 24 (2012) 18051833.

[26] Z. Xu, C. Gao, Acc. Chem. Res. 47 (2014) 1267-1276.

[27] R. Cruz-Silva, A. Morelos-Gomez, H.I. Kim, H.K. Jang, F. Tristan, S. Vega-Diaz, et al., ACS Nano. 8 (2014) 5959-5967.

[28] R. Jalili, S.H. Aboutalebi, D. Esrafi, R.L. Shepherd, J. Chen, S. Aminorroayayamini, et al., Adv. Funct. Mater. 23 (2013) 5345-5354.

[29] S. Zhang, M.L. Minus, L. Zhu, C.P. Wong, S. Kumar, Polymer 49 (2008) 13561364. 
[30] J.P. Abdou, G.A. Braggin, Y. Luo, A.R. Stevenson, D. Chun, S. Zhang, ACS Appl. Mater. Interfaces. 7 (2015) 13620-13626.

[31] Y. Gao, M. Xie, L. Liu, J. Li, J. Kuang, W. Ma, et al., Polymer 54 (2013) 456-463.

[32] Y. Gao, Y. Wu, M. Liang, Q. Fu, J. Appl. Polym. Sci. 132 (2015) 42119 (1-6).

[33] H. Yue, A. Monreal-Bernal, J.P. Fernández-Blázquez, J. Llorca, J.J. Vilatela, Sci. Rep. 5 (2015) 16729.

[34] S. Zhang, W. Lin, L. Zhu, C.-P. Wong, D.G. Bucknall, Macromol. Chem. Phys. $211(2010) 1348-1354$.

[35] H. Li, S. Yan, Macromolecules. 44 (2011) 417-428.

[36] E. Lezak, Z. Bartczak, A. Galeski, Macromolecules. 39 (2006) 4811-4819.

[37] H. Bai, Y. Wang, Z. Zhang, L. Han, Y. Li, L. Liu, et al., Macromolecules. 42 (2009) 6647-6655.

[38] J. William S. Hummers, R.E. Offeman, J. Am. Chem. Soc. 80 (1958) 1339.

[39] J.J. Vilatela, E. Kandel, ACS Nano. 9 (2015) 7392-7398.

[40] H. Quan, Z. Li, M. Yang, R. Huang, Compos. Sci. Technol. 65 (2005) 999-1021.

[41] C. Wu, M. Chen, J. Karger-Kocsis, Polymer 42 (2001) 199-208.

[42] X. Sun, H. Li, J. Wang, S. Yan, Macromolecules. 39 (2006) 8720-8726.

[43] S.Z.D. Cheng, B. Lotz, Polymer 46 (2005) 8662-8681.

[44] E.J. Clark, J.D. Hoffman, Macromolecules. 17 (1984) 878-885.

[45] X. Sun, H. Li, X. Zhang, D. Wang, J.M. Schultz, S. Yan, Macromolecules. 43 (2010) 561-564.

[46] X. Sun, H. Li, I. Lieberwirth, S. Yan, Macromolecules. 40 (2007) 8244-8249.

[47] H.B. Chen, J. Karger-Kocsis, J.S. Wu, J. Varga, Polymer. 43 (2002) 6505-6514. 
[48] C. Wang, C.-R. Liu, Polymer. 40 (1999) 289-298.

[49] X. Gao, J. Jang, S. Nagase, J. Phys. Chem. C. 114 (2010) 832-842.

[50] M. Acik, G. Lee, C. Mattevi, A. Pirkle, R.M. Wallace, M. Chhowalla, et al., J. Phys. Chem. C. 115 (2011) 19761-19781.

[51] Y. Cai, J. Petermann, H. Wittich, J. Appl. Polym. Sci. 65 (1997) 67-75.

[52] J.Z. Xu, G.J. Zhong, B.S. Hsiao, Q. Fu, Z.M. Li, Prog. Polym. Sci. 39 (2014) 555593.

[53] S. Pegel, M. Claes, D. Bonduel, Macromol. Rapid Commun. 29 (2008) 244-251.

[54] D.W. Van Krevelen, K. Te Nijenhuis, Properties of Polymers, 2009.

[55] A.H. Barber, S.R. Cohen, H. Daniel Wagner, Phys. Rev. Lett. 92 (2004) 1861031.

[56] N.H. Kim, B.J. Kim, Y. Ko, J.H. Cho, S.T. Chang, Adv. Mater. 25 (2013) 894898. 